\title{
Relation between the Atmospheric Boundary Layer and Impact Factors under Severe Surface Thermal Conditions
}

\author{
Yinhuan Ao, ${ }^{1}$ Jiangang Li, ${ }^{2,3}$ Zhaoguo Li, ${ }^{1}$ Shihua Lyu, ${ }^{1,4}$ \\ Cailian Jiang, ${ }^{5}$ and Minzhong Wang ${ }^{2,3}$ \\ ${ }^{1}$ Key Laboratory of Land Surface Process and Climate Change in Cold and Arid Regions, \\ Northwest Institute of Eco-Environment and Resources, Chinese Academy of Sciences, Lanzhou 730000, China \\ ${ }^{2}$ Institute of Desert Meteorology, CMA, Urumqi 830002, China \\ ${ }^{3}$ Center of Central Asian Atmospheric Science Research, Urumqi 830002, China \\ ${ }^{4}$ School of Atmospheric Sciences, Chengdu University of Information Technology, Chengdu 610225, China \\ ${ }^{5}$ Wujiaqu Meteorology Bureau, Wujiaqu 831300, China \\ Correspondence should be addressed to Jiangang Li; shzljg_qxj@163.com
}

Received 30 August 2016; Revised 24 December 2016; Accepted 17 January 2017; Published 20 February 2017

Academic Editor: Yoshihiro Tomikawa

Copyright (C) 2017 Yinhuan Ao et al. This is an open access article distributed under the Creative Commons Attribution License, which permits unrestricted use, distribution, and reproduction in any medium, provided the original work is properly cited.

This paper reported a comprehensive analysis on the diurnal variation of the Atmospheric Boundary Layer (ABL) in summer of Badain Jaran Desert and discussed deeply the effect of surface thermal to ABL, including the Difference in Surface-Air Temperature (DSAT), net radiation, and sensible heat, based on limited GPS radiosonde and surface observation data during two intense observation periods of experiments. The results showed that (1) affected by topography of the Tibetan Plateau, the climate provided favorable external conditions for the development of Convective Boundary Layer (CBL), (2) deep CBL showed a diurnal variation of three- to five-layer structure in clear days and five-layer ABL structure often occurred about sunset or sunrise, (3) the diurnal variation of DSAT influenced thickness of ABL through changes of turbulent heat flux, (4) integral value of sensible heat which rapidly converted by surface net radiation had a significant influence on the growth of CBL throughout daytime. The cumulative effect of thick RML dominated the role after CBL got through SBL in the development stage, especially in late summer, and (5) the development of CBL was promoted and accelerated by the variation of wind field and distribution of warm advection in high and low altitude.

\section{Introduction}

The ABL is one of the important physical characteristics of the Land-Atmosphere interaction, and formation and development of $A B L$ are related to surface fluxes such as net radiation and sensible heat. In addition, it plays an important role in cloud formation, rain production, and other feedback in the coupled system $[1,2]$. To get more data, Eddy Covariance (EC, hereinafter) System was used widely for measuring surface fluxes of momentum, sensible heat, and water vapour in the field experiments [3], which are key to the understanding and prediction of other processes taking place within the $\mathrm{ABL}$ $[4,5]$. The thickness of ABL is also one of the important physical parameters of atmospheric numerical model and environmental assessment [6]. However, ABL parameterization scheme is weak part in various numerical weather models and this leads to some errors in certain parameter predictions $[7,8]$.

The previous study shows that the thickness of CBL ranges from $1 \mathrm{~km}$ to $2 \mathrm{~km}$ in humid area through certain point observation or boundary layer statistics [9-11], while in the dry areas with severe surface thermal activity, such as western Sahara, the Arabian Peninsula Desert, the Taklimakan Desert, and the Gobi Desert (in Mongolia and Northwest China), the CBL thickness can stretch over $4 \mathrm{~km}$ in daytime [12-14]. Over recent years, the study on ABL characteristics 


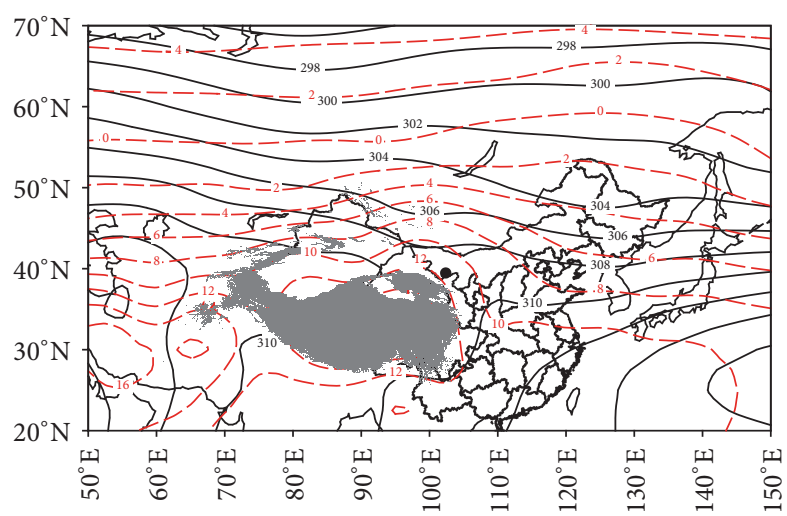

(a)

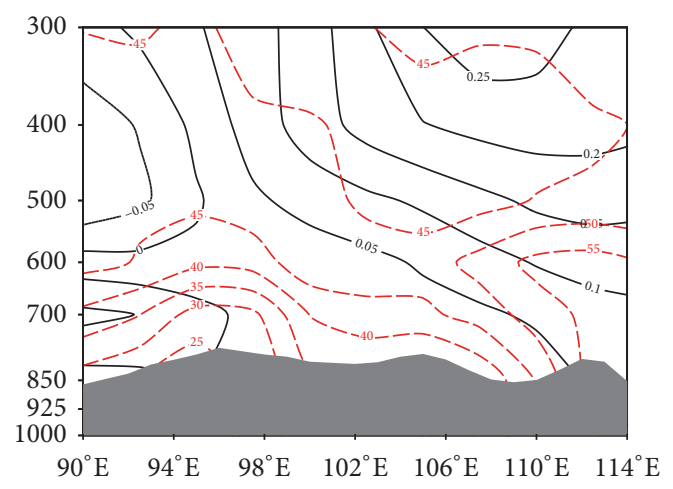

(b)

Figure 1: (a) $700 \mathrm{hPa}$ mean atmospheric circulation field during the last 40 years (solid line: geopotential height, unit: gpm; dash line: temperature, and unit: Celsius degree) and (b) mean vertical velocity and relative humidity during the last 40 years along $40^{\circ} \mathrm{N}$ (solid line: vertical velocity, unit: $\mathrm{cm} \cdot \mathrm{s}^{-1}$; dash line: relative humidity, unit: \%).

under special geographical conditions and extreme climates exceeded people's expectation [15]. According to the study by Gamo et al. (1994), the atmosphere with thick CBL often has a weakly stable and nearly neutral stratification (RML) in desert in the whole; and Flamant et al. [16] found that the RML in Sahara can be maintained for a whole day sometimes. Many other scientists hold the view that the existence and maintenance of RML exert a key influence on the development of CBL $[5,12,17,18]$.

Compared with the Sahara, the Northwest China area is far from the sea and characterized by more complicated topography and drier climate, which makes ABL extremely special [19]. Since 1990s, the ABL in the Hexi Corridor, Dunhuang Gobi Desert, and the Taklimakan Desert are observed and researched by many scientists [14, 19-22]. The CBL thickness on clear days of summer in these regions is more than $4 \mathrm{~km}$; meanwhile the preliminary research on the origin of thick CBL was also conducted [23-25]. Based on the radiosonde data from Dunhuang Gobi Desert, Zhang et al. [26] found, whether in summer or winter, diurnal variation of the surface net radiation, DSAT, and sensible heat flux correlates well with the thickness of CBL and deemed that DSAT is an important factor for the origin of thick CBL. Adopting the numerical model, Zhao [27] demonstrated that in summer the contribution of sensible heat to the development of CBL in arid areas in western China is greatest, but it is hard to explain only by this. However, Han et al. [28] and others [5, 29, 30] believed that the RML has significant impact on the formation of thick CBL in desert.

In order to learn more about the formation regulation of $\mathrm{ABL}$ and the main causes for the thick CBL in northwestern desert region of China, the scientists conducted the observation experiment in the limited IOP in the Badain Jaran Desert in August 2009 and July 2012, respectively. In this study, the development process of CBL was analyzed systematically and formation of $\mathrm{CBL}$ in the desert region was discussed by use of GPS radiosonde data and ground-based material obtained from the two experiments.

\section{Introductions to Observation Experiment}

2.1. Climate Background of Observation Area. Badain Jaran Desert is the second largest desert in China, covering an area of $5.2 \times 10^{5} \mathrm{~km}^{2}$. Lying on the north rim of the Hexi Corridor, it is vital to be passed through by the northern branch airflow of circulating westerly generated by the Tibetan Plateau. In summer, it is comprehensively affected by both the East Asian summer monsoon and the compensated downdraft of the northern slope of the Plateau, which indicates that the development of ABL in this area is more complicated. Annual precipitation is only $40-80 \mathrm{~mm}$ with most rain falling in the summer while the evaporation is $40-80$ times the amount of precipitation, and the maximum temperature is up to $38-43^{\circ} \mathrm{C}$.

From the mean atmospheric circulation field of $700 \mathrm{hPa}$ in summer from 1962 to 2012 based on the NCEP monthly reanalysis, it is shown that (see Figure 1(a)) Badain Jaran Desert is controlled by the warm shallow high ridge in westerly, which are similar at the $500 \mathrm{hPa}$ level. The high ridge formed by the flow around the Plateau imposes great influence on the local climate by the topography of the Tibetan Plateau. The circulation collocation in high and low altitude is regarded as the important reason resulting in dry and rainless climate in the desert region. From Figure 1(b), it is shown that the values of vertical velocity above the desert are basically positive and gradually increase with the altitude; the air relative humidity in lower layer of the troposphere only ranges from $30 \%$ to $35 \%$, demonstrating the prevailing of sinking motion and drier air in middle-to-low levels of tropopause.

2.2. Introduction to Observation Experiment. The experiment of "Badain Jaran Desert Land-Atmosphere Interaction Observation Experiment" is a comprehensive field observation project supported by the National Natural Science Foundation of China (NSFC). The experiment was conducted in the southeastern Badain Jaran Desert $\left(39^{\circ} 28.124^{\prime} \mathrm{N}\right.$, $102^{\circ} 22.365^{\prime} \mathrm{E}$, with altitude of $1,415 \mathrm{~m}$ ). The observation site is typical desert underlying surface, and desert-Gobi transition 
TABLE 1: Observation equipment and installment height of eddy covariance system.

\begin{tabular}{|c|c|c|c|}
\hline Observational item & Instrument type & Manufacturer & Sensor height $(\mathrm{m})$ \\
\hline Wind & CSAT3 & Campbell/USA & 3.0 \\
\hline \multirow{2}{*}{ Vapor/CO $\mathrm{CO}_{2}$} & Li-7500 (2009) & LI-COR/USA & \multirow{2}{*}{3.0} \\
\hline & EC150 (2012) & Campbell/USA & \\
\hline \multirow{2}{*}{ Air temperature/humidity } & HMP45C (2009) & \multirow{2}{*}{ Vaisala/Finland } & \multirow{2}{*}{3.0} \\
\hline & HMP155 (2012) & & \\
\hline \multirow{2}{*}{ Radiation } & CNR1 (2009) & \multirow{2}{*}{ Kipp \& Zonen/Holland } & \multirow{2}{*}{1.5} \\
\hline & CNR4 (2012) & & \\
\hline \multirow{2}{*}{ Soil heat flux } & \multirow{2}{*}{ HFP01 } & \multirow{2}{*}{ Hukseflux/Holland } & -0.05 \\
\hline & & & -0.20 \\
\hline \multirow{4}{*}{ Soil temperature/humidity } & \multirow{4}{*}{ 109L/CS616 } & \multirow{4}{*}{ Campbell/USA } & -0.05 \\
\hline & & & -0.10 \\
\hline & & & -0.20 \\
\hline & & & -0.40 \\
\hline
\end{tabular}

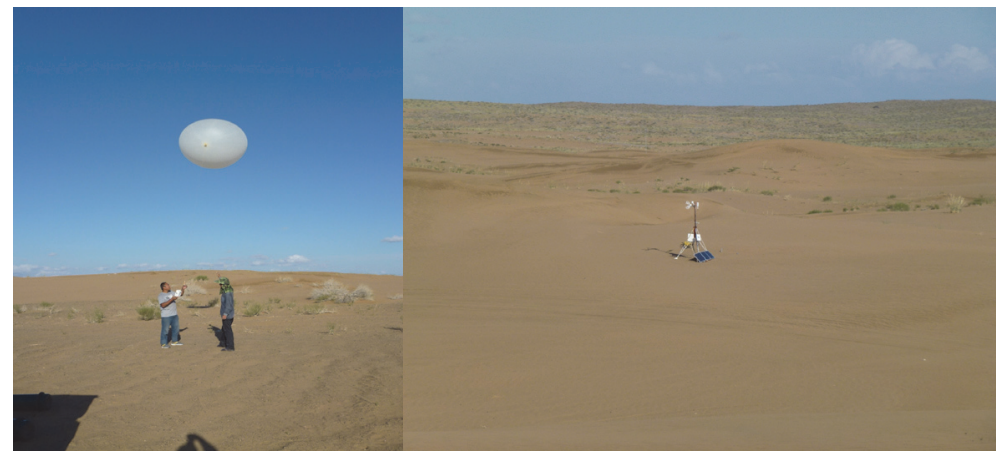

FIGURE 2: Geographic environment and ABL experiment observation field in Badain Jaran taken on July 4, 2012.

zone is $1 \mathrm{~km}$ far from the southern part of the observation field, with a few sparse vegetation. The terrain is most flat or slightly undulated, so it can be considered as homogenous surface. (As shown in Figure 2).

The experiments were performed almost in the same place from July to September 2009 and in early July of 2012, respectively. In 2009, the tethered balloon (TTS-111, Vaisala Inc., USA) and the GPS sonde (RS-92, Vaisala Inc., USA) were applied for sounding observation. In 2012, the GPS sonde (IMet-1-AB, International Met Systems Inc., USA) and microwave radiometer (RPG-HATPRO-G3, RPG Inc., Germany) were utilized. A set of eddy correlation systems was built for surface fluxes observations in two experiments. It is shown in Table 1 for the model of the instrument and the lifting height. The data acquisition frequency of tethered balloon is $1 \mathrm{~Hz}$ and the vertical resolution ranges from $1 \mathrm{~m}$ to $3 \mathrm{~m}$. The frequencies of RS-92 and IMet-1-AB GPS sonde are $0.5 \mathrm{~Hz}$, $1 \mathrm{~Hz}$, respectively, and the vertical resolution is about $10 \mathrm{~m}$.

\section{Data and Methods}

3.1. Data Selection. The radiosonde observation was primarily concentrated from August 26 to 31, 2009, in the experiment of 2009. During this period, August 26 and August 30 were typically clear, August 27 and August 29 were partly cloudy,
August 31 was cloudy with occasional shower, and the wind velocity was too strong to observe on August 28. In 2012 the sounding observation frequency was enhanced six times every day, which were at 2300, 0200, 0500, 0800, 1100, and 1500 UTC. During this period, July 3 was partly cloudy, July 4 , July 5 , and July 7 were clear, and there was light rain and then it turned clear in July 6 . Therefore, considering the time synchronism of two observation instruments, August 30 in 2009 and July 4 in 2012 were selected to represent the typical clear day in midsummer and late summer, respectively, for the comparison analysis because it was not affected by weather changes. Obviously, the study has the limitations due to lack of enough observation times.

3.2. Methods. The thickness of ABL was determined mainly by the potential temperature profile obtained from radiosonde, considering the greater effect of thermal condition on the ABL in the desert and the notable characteristics of potential temperature profile $[31,32]$. However, owing to larger space of the radiosonde instrument drift, temperature detection can be affected by the local small cloud group in the atmosphere; the observed potential temperature profile is characterized by the nonsmooth curve shape which is disturbed by vertical movement $[6,33]$, leading to the uncertainty of ABL layer classification. So the specific humidity and 


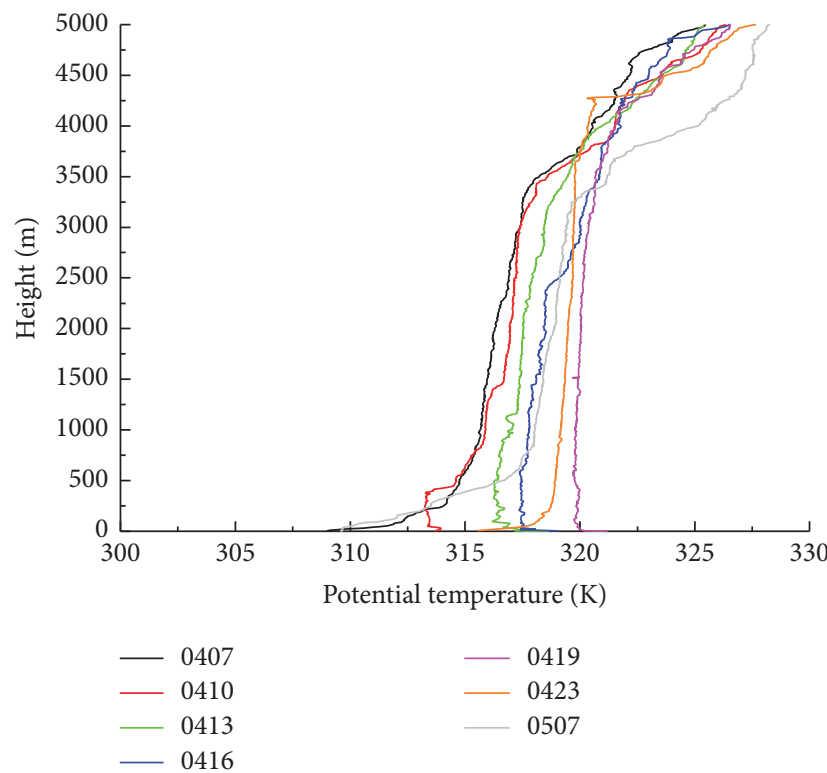

(a)

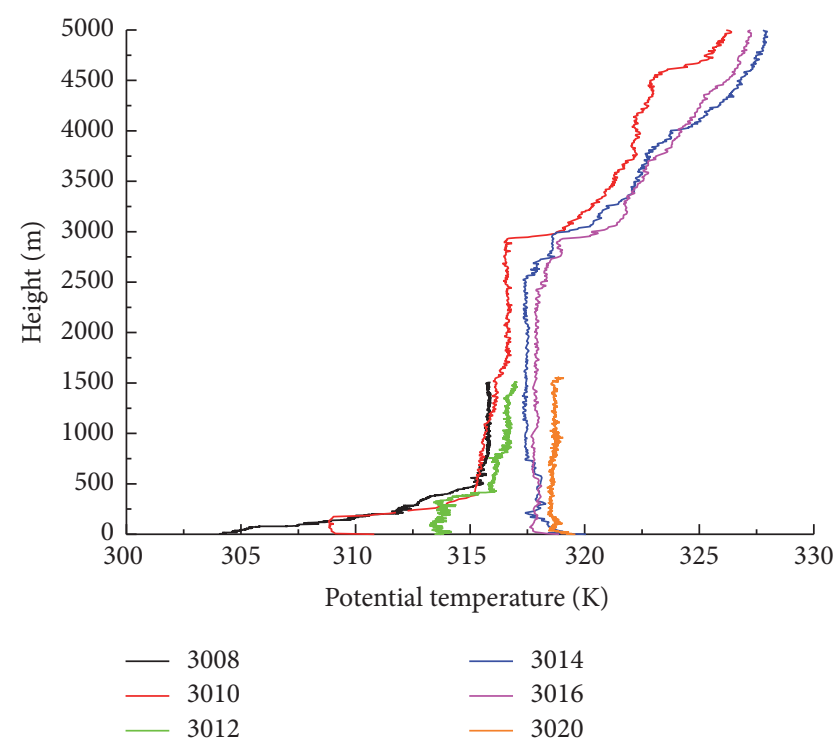

(b)

Figure 3: Comparison of potential temperature profile on (a) July 4, 2012, and (b) August 30, 2009. The observation time (UTC) of each profile is showed in the legend.

wind velocity profile method was used as an auxiliary method to reduce the uncertainty.

In the daytime (at 0200, 0500, 0800, and 1100 UTC), potential temperature profile decreased gradually with the increasing height when the surface heated intensely at noon; this layer was defined as Superadiabatic Layer (SL, hereinafter). Above it, the Potential Temperature Gradient (PTG, hereinafter) was less than $0.1^{\circ} \mathrm{C} \cdot(100 \mathrm{~m})^{-1}$, which was Mixed Layer (ML, hereinafter). ML and SL constitute CBL. The temperature inversion layer in which PTG exceeded $0.3^{\circ} \mathrm{C} \cdot(100 \mathrm{~m})^{-1}$ above CBL was Capping Inversion Layer (CIL, hereinafter). At night (at 2300 and 1500 UTC), the definition of Residual Capping Inversion Layer (RCIL, hereinafter) was the same as CIL; the layer that was close to the ground with the inversion intensity exceeding $0.4^{\circ} \mathrm{C} \cdot(100 \mathrm{~m})^{-1}$ was defined as the Stable Boundary Layer (SBL, hereinafter). The layer above the SBL and under RCIL which remains neutral at night was defined as residual mixed layer (RML, hereinafter) $[23,34]$.

The EC observation data were processed for basic quality control including outlier removal, delay time correction, virtual temperature correction and WPL correction, and the output set of data every thirty minutes. The momentum flux $\tau$, the sensible heat flux $H$, and latent heat flux $L E$ are obtained through the EC method [35]:

$$
\begin{aligned}
\tau & =\rho u^{2}=\rho\left(\left(\overline{w^{\prime} u^{\prime}}\right)^{2}+\left(\overline{w^{\prime} v^{\prime}}\right)^{2}\right)^{1 / 2}, \\
H & =\rho c_{p} \overline{w^{\prime} \theta^{\prime}} \\
L E & =\rho \lambda \overline{w^{\prime} q^{\prime}} .
\end{aligned}
$$

In the formula, $\rho$ means air density; $c_{p}$ means air specific heat $\left(1004.67 \mathrm{~J} \cdot \mathrm{kg}^{-1} \cdot \mathrm{K}^{-1}\right) ; \lambda$ means coefficient of evaporation latent heat $\left(2440 \mathrm{kPa} \cdot \mathrm{m}^{3} \cdot \mathrm{kg}^{-1}\right) ; \overline{w^{\prime} u^{\prime}}$ and $\overline{w^{\prime} v^{\prime}}$ mean the statistical mean wind speed fluctuation; $\overline{w^{\prime} \theta^{\prime}}$ and $\overline{w^{\prime} q^{\prime}}$ mean the statistical mean temperature and humidity fluctuation, respectively.

\section{Results}

In general, the development of ABL shows obvious diurnal variation in desert area. CBL developed mainly in the daytime and SBL was dominated at night instead. The former is usually significantly thicker than the latter and transition stage between them occurs about sunrise or sunset. It is shown from case study that the development of ABL in the daytime is tied up with the factors including the RML at night, the thermal characteristics of the underlying surface, and atmospheric circulation.

4.1. Boundary Layer Structure. Figure 3 showed the changes of potential temperature profile on August 30, 2009 (data observed from tethered balloon was used as a supplement of GPS observation), and July 4, 2012, respectively. In midsummer (Figure 3(a)), the SBL thickness was higher and exceeded $870 \mathrm{~m}$ on July 4 , where PTG reached $0.8^{\circ} \mathrm{C} \cdot(100 \mathrm{~m})^{-1}$. The RML with thickness of $2,700 \mathrm{~m}$ and smaller PTG indicated that extra-thick CBL maybe occurred in the previous day. As time went on, the CBL formed gradually, then rapidly increased, and finally reached 4,100 m. At 1500 UTC, the SBL was rebuilt, where the thickness reached $800 \mathrm{~m}$ until the next morning. Even in late summer, the CBL in desert was still higher from Figure 3(b). On August 30, the maximum thickness of CBL reached $3,000 \mathrm{~m}$, and SL appeared on the ground layer, demonstrating that the underlying surface thermal effect remained strong. At night, the temperature fell rapidly 


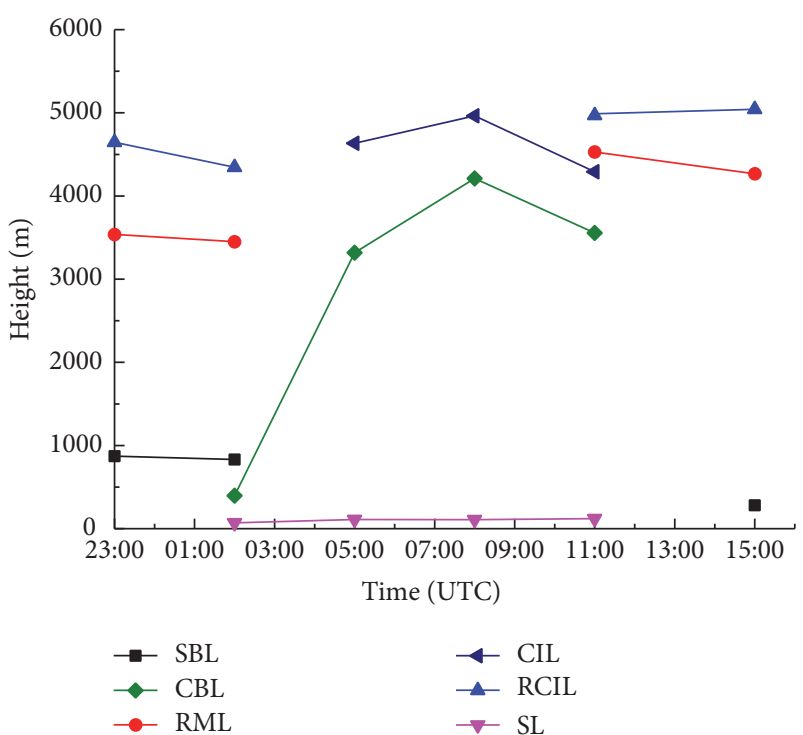

(a)

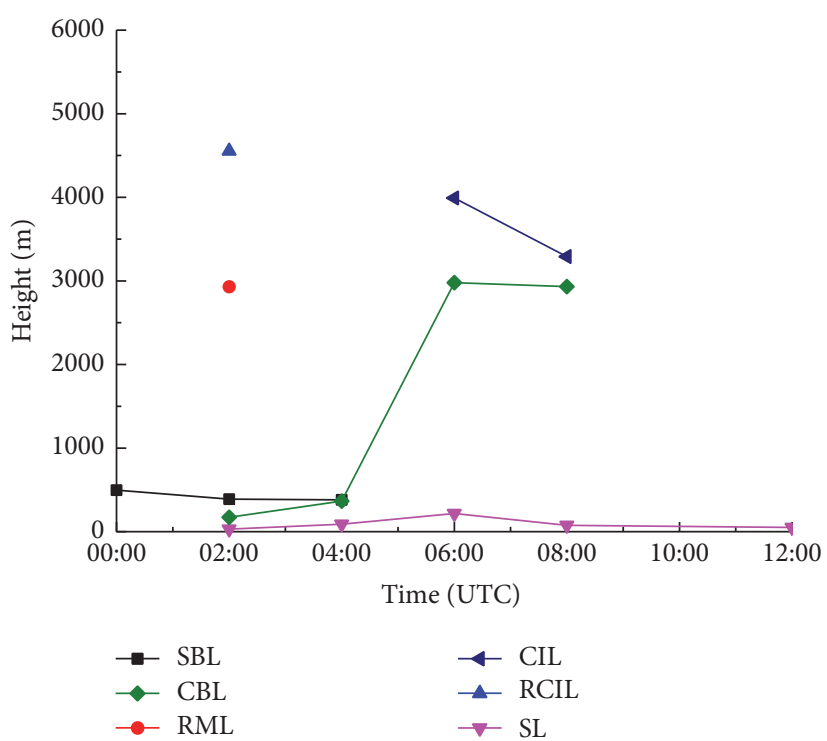

(b)

FIGURE 4: Daily variation of potential temperature structure on (a) July 4, 2012, and (b) August 30, 2009.

with the effect of obvious radiation cooling, making the SBL develop quickly and reached $500 \mathrm{~m}$ in the morning.

As shown in Figure 4, the diurnal variation of ABL structure was further analyzed. It can be seen that, at 2300 UTC in the morning of midsummer, $\mathrm{ABL}$ developed into three layers, namely: SBL, RML, and the RCIL from bottom to top. At 0200 UTC, five-layer structure appeared, namely, SL, ML, SBL, RML, and RCIL [28]. From 0500 to 0800 UTC, SBL and RML disappeared, and ABL changed into three layers again. At 1100 UTC RML and RCIL started recovering; ABL temporarily returned five layers again. With the development of the SBL, ABL developed into three layers again (as shown in Figure 4(a)), thus forming a typical diurnal cycling.

In late summer the diurnal variation of $\mathrm{ABL}$ is similar to the counterpart in midsummer from 0000 to 1200 UTC (Figure 4(b)) except the correspondingly descending altitude in spite of less GPS radiosonde observation times, which is in accordance with the description by Han et al. As can be seen from the above, it was not accidental that five-layer boundary layer structure appeared in the desert with one to two hours before or after the sunset or sunrise from the results of two experiments.

After sunrise, the surface temperature increased rapidly and the thermal convection was vigorous with soil characterized by dry and low heat capacity in desert, CBL can easily get through thinner SBL and enter into RML. Since RML remained the main energy of $\mathrm{ABL}$ and has the similar thermal property with the CBL in the daytime, it becomes a part of the CBL quickly. As a result, the thickness of CBL increased sharply, which showed that the thick RML remaining at night provided the favorable thermal conditions to the rapid development of CBL in the next day. It is also shown from Figure 5 that the occurrence frequency of thick CBL is higher during two observations. The thickness of CBL in another time has approached or exceeded 3,000 $\mathrm{m}$ except for the cloudy or rainy days which affect the development of thermal boundary layer, and SBL was also significant. The fact showed that the thicker CBL was a common phenomenon in desert in summer. Under the favorable sunny condition, CBL was extremely thicker, its thickness fell rapidly in rainy days, but SBL increased correspondingly instead. It was similar to the results observed in Dunhuang Gobi Desert by Zhang and Wang [36], and the cumulative effect of CBL was verified by observation. In addition, numerical modeling study also supported such fact. Adopting the long-time modeling, Shan [37] found that within three to five days the super-thick CBL in arid region of Northwest China was comprehensively formed by the RML effect. Medeiros and Gaster [38] also deemed that the heat budget of RML, especially the cooling rate, has a great nonlinear influence on the development of boundary layer in the daytime, and its nature played a key role in determining the daily maximum thickness of $\mathrm{ABL}$.

4.2. Influence of Surface Thermal. The cumulative effect of RML has a significant effect on the development of CBL only after CBL got through the SBL. But the development of CBL was closely related to surface thermal action throughout daytime. After being heated by solar radiation, the sandy surface transferred the heat into the air quickly through the boundary layer's turbulent motion, controlling the changes of wind, temperature, and humidity and then changing the thickness of the boundary layer. Among them, the surface net radiation was the fundamental of surface thermal energy, DSAT resulted from surface radiation heating (or cooling), and the surface layer's turbulent heat transfer are regarded as the important driving forces for formation and development of ABL's thermal convection. Therefore, it is very necessary to accurately understand the effects of surface heating on ABL. The surface radiation surplus (deficit) may lead to temperature increase (reduction), causing DSAT and promoting 


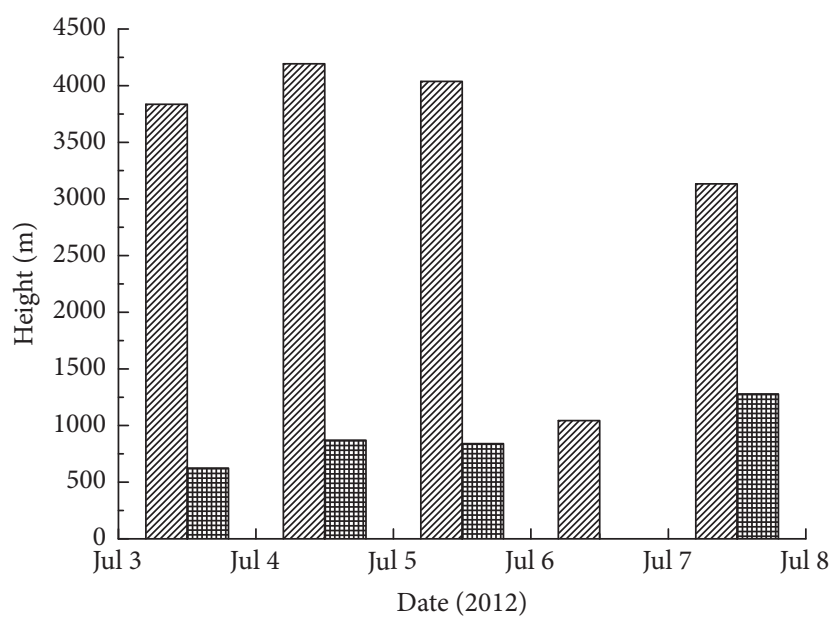

UTIIA CBL
淟册 SBL

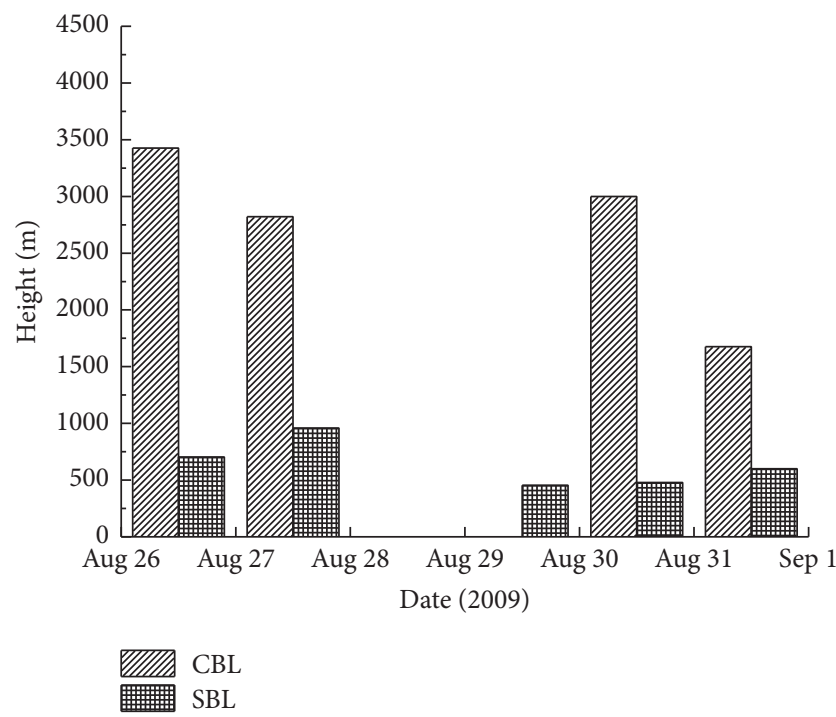

(b)

FIGURE 5: Daily maximum thickness variation of CBL and SBL: (a) midsummer in 2012 and (b) late summer in 2009.

the development of ABL at last. In the experiment of 2009, surface infrared thermometer was used for the measurement of surface temperature, but it was absent in 2012. For getting DSAT in the period of two experiments, the surface temperature must be calculated firstly by use of the following formula:

$$
T_{g}=\left[\frac{R_{\mathrm{lu}}-\left(1-\varepsilon_{g}\right) R_{\mathrm{ld}}}{\varepsilon_{g} \sigma}\right]^{1 / 4} .
$$

In the formula, $\varepsilon_{g}$, the surface emissivity, was $0.95, \sigma$, the Stefan-Boltzmann constant, was set to $5.67 \times 10^{-8} \mathrm{~W} \cdot \mathrm{m}^{-2} \cdot \mathrm{K}^{-1}$, and $R_{\mathrm{lu}}$ and $R_{\mathrm{ld}}$ were the upward and downward long-wave radiation, respectively. Correlation coefficient between calculated and observed value reached 99\% (figure not shown). Therefore, it can be applied by this equation in 2012 .

Figure 6 showed the corresponding diagram between the diurnal variation of DSAT and the structure of ABL. In order to facilitate the analysis, the thickness of CBL and SBL was expressed as positive and negative value, respectively. As can be seen the diurnal variation of DSAT had a close relationship with the thickness of ABL regardless of midsummer or late summer; that is to say, in the daytime, the greater DSAT is, the thicker CBL would be. On the contrary, the stronger the temperature inversion at night is, the thicker the SBL would be. However, the development of CBL lagged behind DSAT in two periods, respectively, which was $4 \mathrm{~h}$ in midsummer and only $1.5 \mathrm{~h}$ in late summer. From the figure, it is also found that the development patterns of CBL in the two experiments were different. In midsummer, the thickness of CBL gradually increased with the time. But in late summer, the thickness of CBL increased sharply afternoon, demonstrating that the development of CBL may be considerably impacted by the cumulative effect of RML.

DSAT did not directly act on the atmosphere and it influenced the development of the boundary layer through turbulent heat flux. The desert has unique features, such as sparse vegetation and drier soil for low latent heat. Therefore, the net radiation mainly heated the atmosphere through sensible heat after the balance of surface radiation budget, and conversion rate of net radiation to sensible heat flux was an important factor affecting ABL. Figures 6(c) and 6(d) described the relationship among the net radiation, sensible heat flux, and the development of $\mathrm{ABL}$ in midsummer and late summer. From Figure 6(c), it is found that the maximum value of surface net radiation can reach $530 \mathrm{~W} \cdot \mathrm{m}^{-2}$ and the maximum sensible heat flux was up to $270 \mathrm{~W} \cdot \mathrm{m}^{-2}$ in midsummer. The proportion of sensible heat in net radiation was much lower than the counterpart in Dunhuang Gobi Desert; however, the sensible heat peak only lagged behind the net radiation peak value by $0.5 \mathrm{~h}$, which was the same to the phenomenon at Loess Plateau [39], shorter than $0.8 \mathrm{~h}$ to $1.5 \mathrm{~h}$ in general areas instead [40]. It showed that the net radiation rapidly converted to sensible heat and heated the atmosphere rapidly in desert area. In late summer, the maximum value of net radiation and sensible heat flux significantly was decreased, and the increase of temperature inversion intensity at night was conducive for formation of thicker SBL (as shown in Figure 6(d)).

The above analysis showed that the sensible heat flux was the principal driving force for the development of CBL in desert. However, the CBL growth did not stop with the sensible heat flux reaching the maximum daily value but generally delayed for some time. The development of ABL was a cumulative process. Therefore, only from the analysis of instantaneous sensible heat diurnal variation was not complete, and the variable, namely, the cumulative value of sensible heat $\left(H_{c}\right.$, hereinafter), needed to be introduced for the study (as shown in Figure 7). For the calculation in this paper, the CBL's corresponding $H_{c}$ started at 1600 UTC and ended at 1100 UTC and 1000 UTC in midsummer and late summer, respectively. The SBL's corresponding $H_{c}$ started 


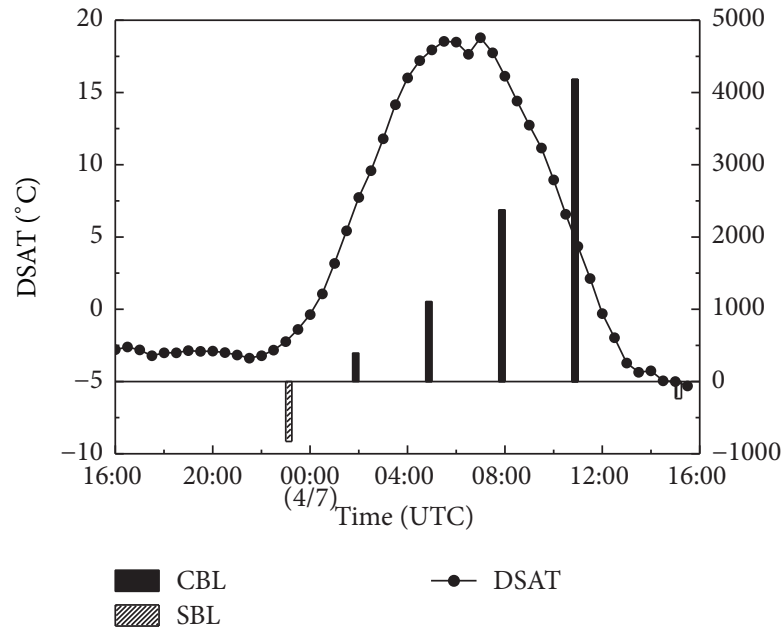

(a)

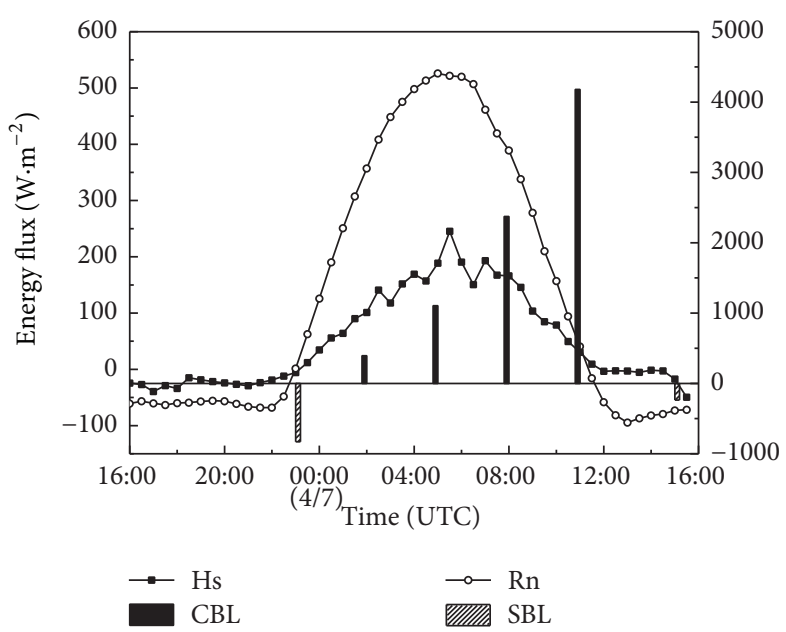

(c)

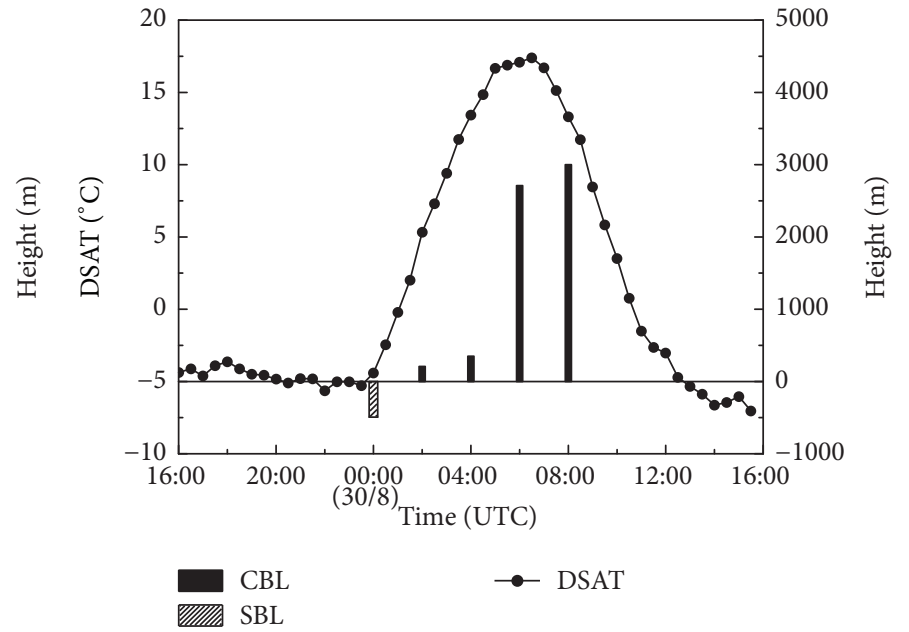

(b)

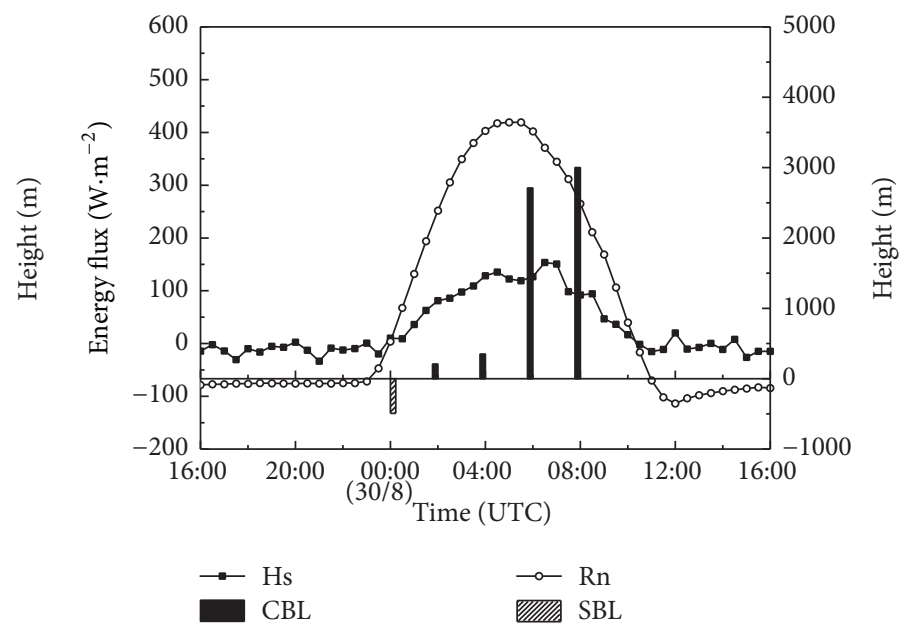

(d)

FIGURE 6: The daily relationship between DSAT, net radiation, sensible heat flux, and ABL on ((a), (c)) July 4, 2012, and ((b), (d)) August 30, 2009.

from 1200 UTC and ended at 0000 UTC in the next day. Figure 7(a) showed the relationship of the development of CBL and $H_{c}$ in midsummer. From the figure, it can be seen that the thickness of CBL rapidly increased with $H_{c}$ increase when $H_{c}$ was less than $2,000 \mathrm{~W} \cdot \mathrm{m}^{-2}$, and the variance of the fitting curve was smaller. After exceeding this value, the variance obviously increased and the variation of CBL thickness was very discrete with the changes of $H_{c}$, demonstrating that $H_{c}$ has a little effect on the thickness of CBL in this stage. It can be found that the similar phenomenon appeared in late summer except the reduced threshold (as shown in Figure 7(b)). The above-mentioned phenomenon demonstrated that the CBL can rapidly develop in the daytime as long as the atmosphere can obtain the energy for getting through the SBL, the changes of sensible heat would have less influence on the thickness of CBL after that. It also showed that the thickness of CBL depended on the time integral value of heat flux after sunset, but not the instantaneous flux value.
Figure 7(c) showed that the relationship between the SBL and $H_{c}$ was more complicated at night. In midsummer, it was evident that $H_{c}$ had a significant influence on SBL when $H_{c}$ varied from -100 to $0 \mathrm{~W} \cdot \mathrm{m}^{-2}$. After exceeding this range, the thickness of boundary layer changed less with $H_{c}$, presenting a nonlinear correlation, which was nearly consistent with other study results. However, linear relationship (as shown in Figure 7(d)) between them was showed in late summer. Owing to the shortage of radiosonde data in 2009, it was hard for us to give explicit reasons for such difference.

Though the sensible heat flux was major thermal factor affecting ABL, it has different effect on SBL and CBL. Its influence on the SBL in late summer was significantly higher than that in midsummer. For CBL, it presented similar nonlinear relationship with the sensible heat flux in the two experiments, where the effect of sensible flux was obvious on CBL in the initial stage of development of CBL and tended to 


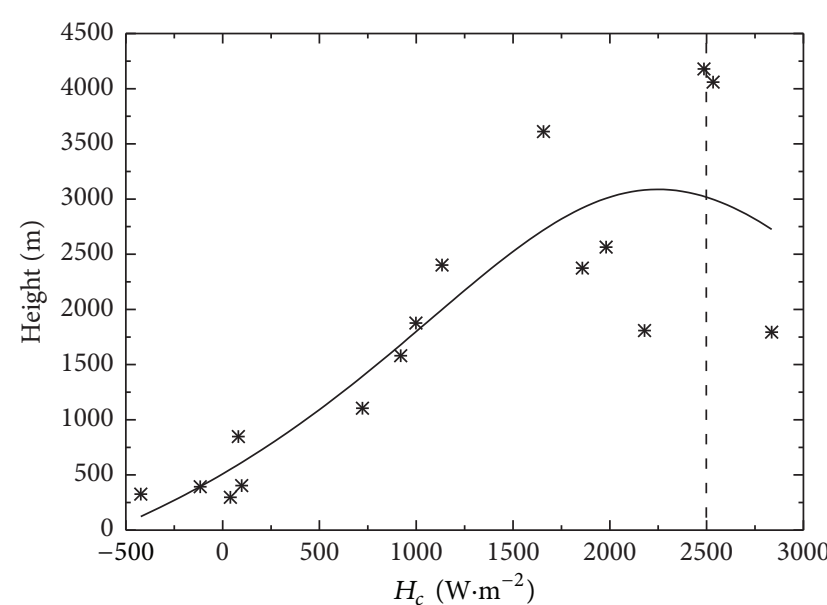

(a)

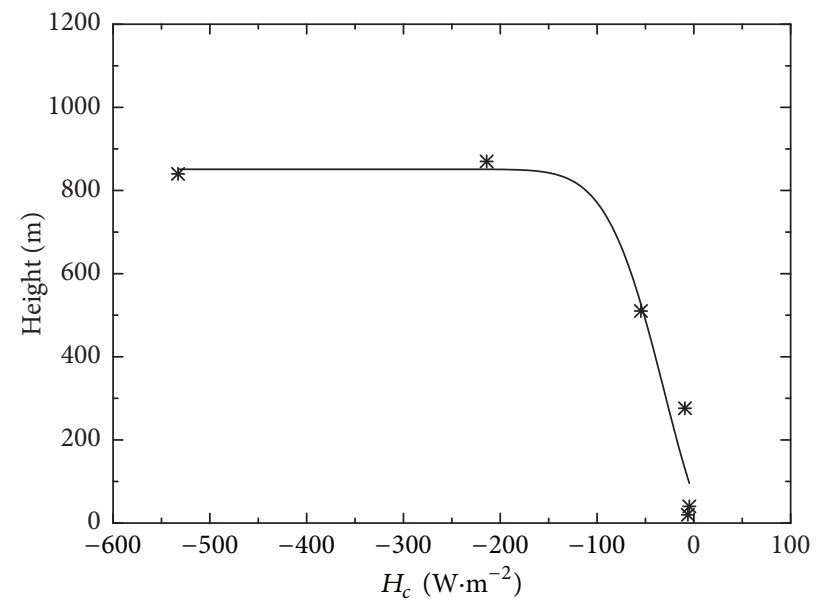

(c)

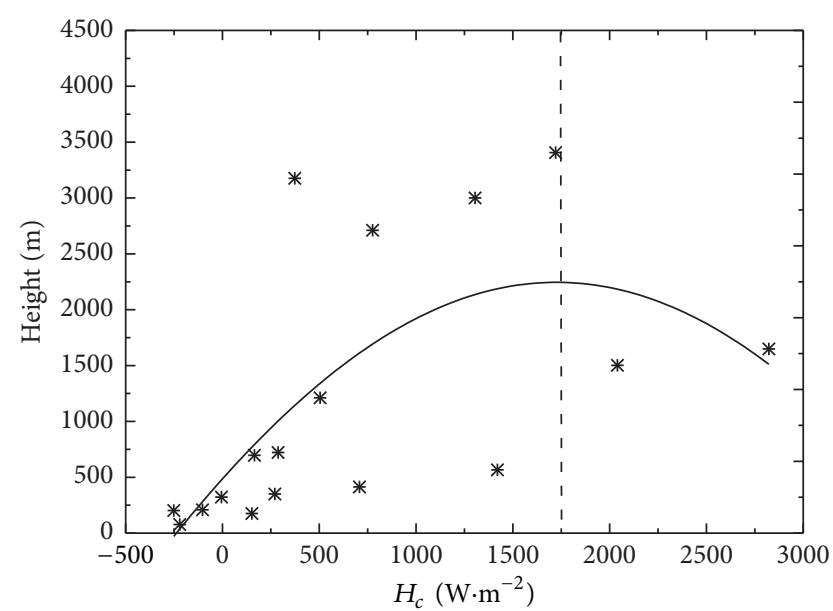

(b)

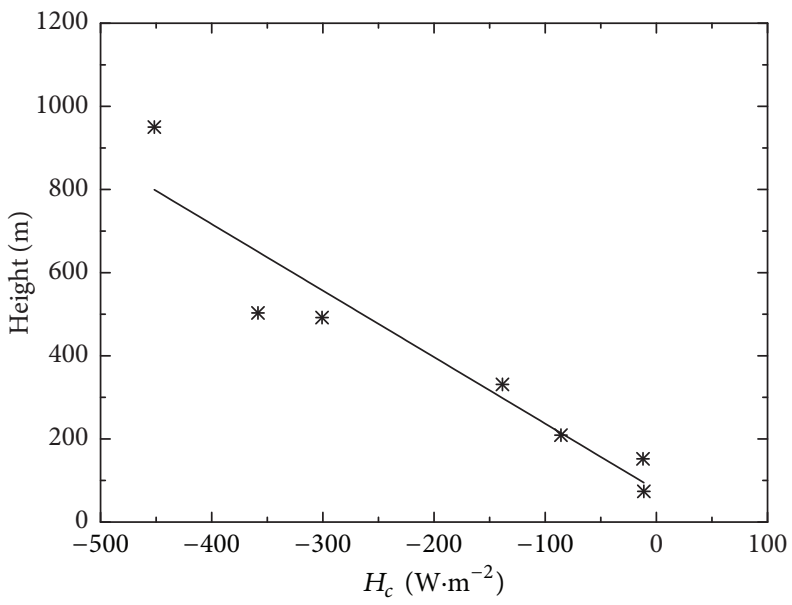

(d)

Figure 7: The relationship between (a) CBL and $H_{c}$ in midsummer in 2012; (b) CBL and $H_{c}$ in late summer in 2009; (c) SBL and $H_{c}$ in midsummer in 2012; (d) SBL and $H_{c}$ in late summer in 2009.

weaken in the following stage, demonstrating that the other physical variables also affect the development of CBL.

\subsection{Influences of Atmospheric Circulation}

4.3.1. Influence of Wind Fields on ABL. The wind direction or wind speed shear was able to speed up the motion of turbulent and molecule from ground up, making the heat convection rapidly diffuse to high altitude, which was favorable for formation of deep boundary layer.

Figures $8(\mathrm{a})$ and $8(\mathrm{~b})$ showed $\mathrm{ABL}$ horizontal wind vertical structure in Badain Jaran Desert. From the figure, there was obvious wind speed and wind direction shear in the vertical direction, and wind speed was bigger. According to statistics, the maximum daily wind speed of boundary layer exceeded $15 \mathrm{~m} \cdot \mathrm{s}^{-1}$ in midsummer and varied from $10 \mathrm{~m} \cdot \mathrm{s}^{-1}$ to $15 \mathrm{~m} \cdot \mathrm{s}^{-1}$ in late summer. The strong wind speed or wind direction shear weakened the intensity of temperature inversion on the top of CBL by increasing the diffusion and entrainment effect and took the sensible heat flux from the ground to the upper air and thus improved the convection efficiency. This would make CBL much deeply enhanced and provided a favorable dynamic environment to formation of ultra-thick CBL. This can be confirmed by the observations that the altitude of CBL was basically the same as that of the most intense wind speed shear.

4.3.2. Influence of Atmospheric Circulation. The research on the effect of vertical motion on boundary layer development is less in the past. Although the large-scale vertical motions could not change the total mass of $\mathrm{ABL}$, it contributed to its redistribution in the horizontal direction. Cuesta et al. [41] discovered that, in summer although the stratification was weak and the altitude of CBL can reach $5 \mathrm{~km}$ to $6 \mathrm{~km}$ in the western part of the Sahara Desert, due to the influence of Harmattan Wind caused by the subtropical high over the Mediterranean Sea, relatively stable stratification was formed, which inhibited the development of CBL in the middle part of the Sahara. The divergence was a physical variable expressing the atmospheric ascending and sinking movement well. 


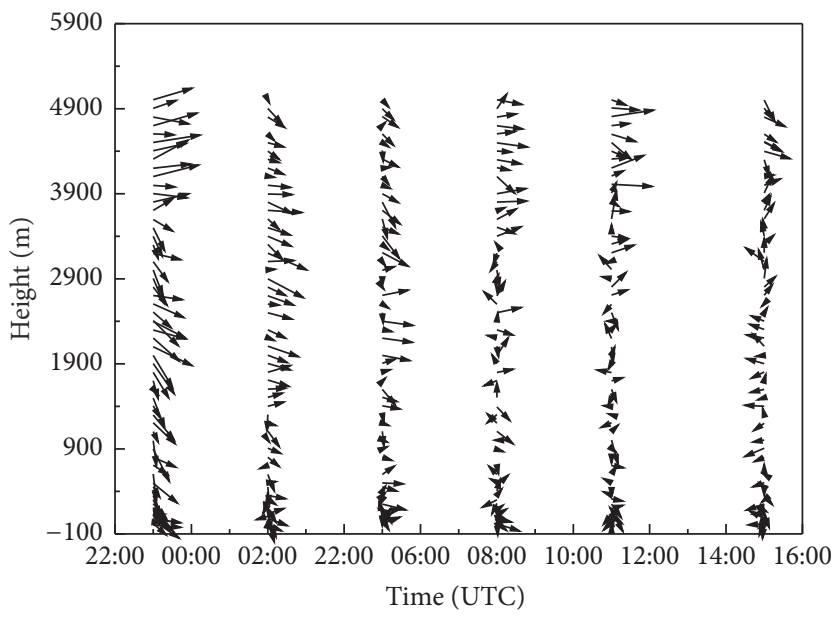

$\longrightarrow 13 \mathrm{~m} \cdot \mathrm{s}^{-2}$

(a)

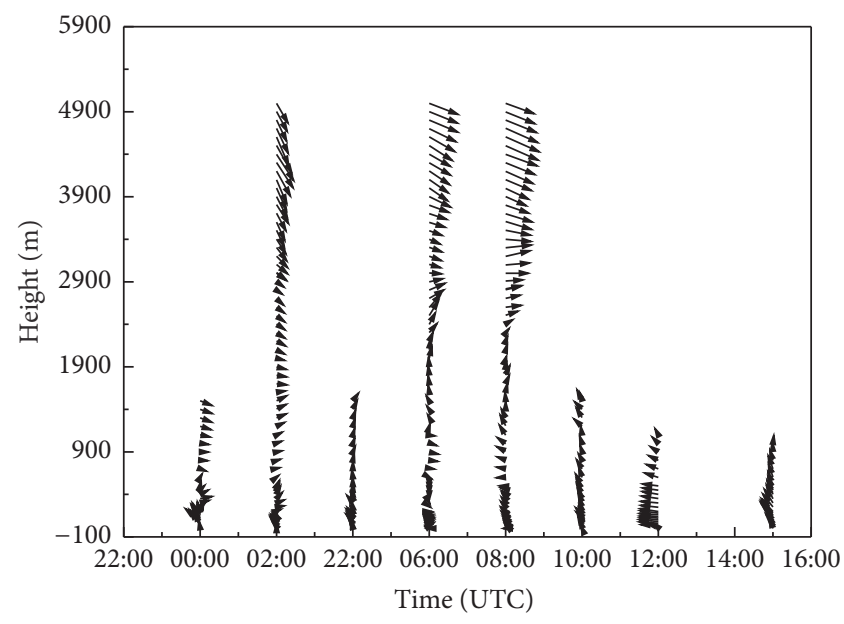

$\longrightarrow 13 \mathrm{~m} \cdot \mathrm{s}^{-2}$

(b)

FIgURE 8: The vertical structure of ABL's horizontal wind field on (a) July 4, 2012, and (b) August 30, 2009.

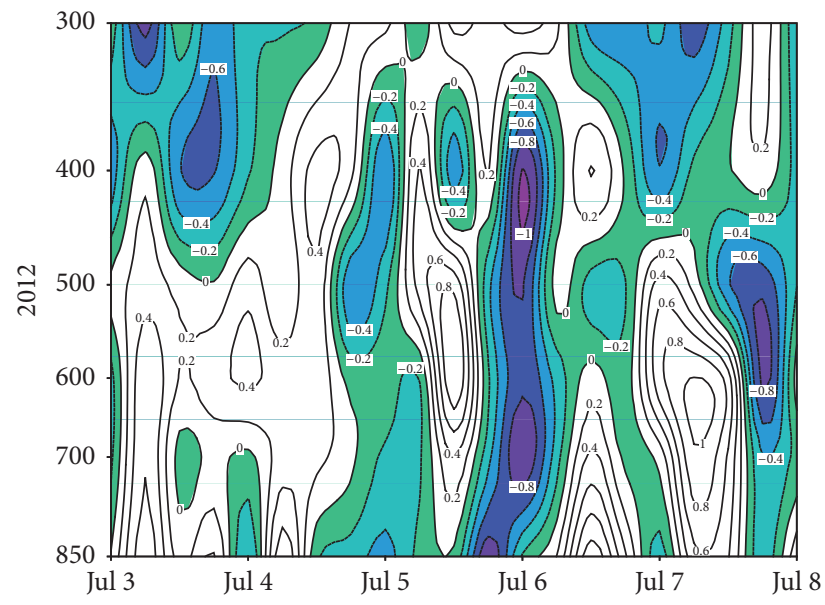

(a)

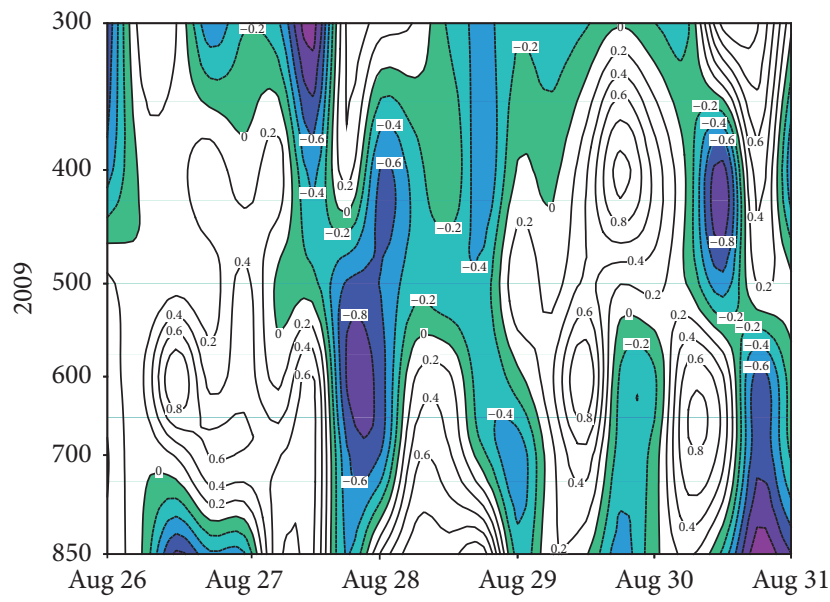

(b)

FIGURE 9: The vertical variation of divergence field during the observation period (a) midsummer and (b) late summer.

Applying the reanalysis data of NCEP $1^{\circ} \times 1^{\circ}$, the vertical divergence field, the geopotential height with temperature field was plotted during the experiment.

The altitude of observation point was close to $1,500 \mathrm{~m}$, so the ordinate was marked from $850 \mathrm{hPa}$ in Figure 9. It is obviously shown from Figure 9(a) that, in July 3 5, positive divergence extended higher close to $400 \mathrm{hPa}$ on the day of July 3 and exceeded $300 \mathrm{hPa}$ on July 4 and July 5 . On July 6 , affected by the light rain, the divergence firstly became negative and then positive with relatively low altitude. On July 7 , the altitude of the positive divergence area increased again and exceeded $500 \mathrm{hPa}$. The same phenomenon was also found during the observation period in late summer. That is to say, the higher the positive divergence region and the larger the value are, the higher the altitude of CBL would be (as shown in Figure 9(b)). The positive divergence represented the sinking air, which indicated that it was clear with intense radiation in favor of further development of turbulence, resulting in increasing CBL height. It showed that the vertical distribution of divergence has a good correspondence with the maximum height of $\mathrm{CBL}$ and had a significant influence on the formation of ABL.

Figure 10 showed the geopotential height field with temperature at $500 \mathrm{hPa}$ and $700 \mathrm{hPa}$ at $0600 \mathrm{UTC}$ of typical clear days in midsummer and late summer, respectively. On July 4, the warm advection existed in the middle and high level atmosphere and its intensity at $500 \mathrm{hPa}$ was weaker than that at $700 \mathrm{hPa}$. On August 30, the warm advection was relatively apparent at $500 \mathrm{hPa}$, but the cold advection appeared at $700 \mathrm{hPa}$, which imposed a negative effect on development of ABL. However, the surface was still controlled by thermal depression, thus showing a distribution of warm-cold-warm 


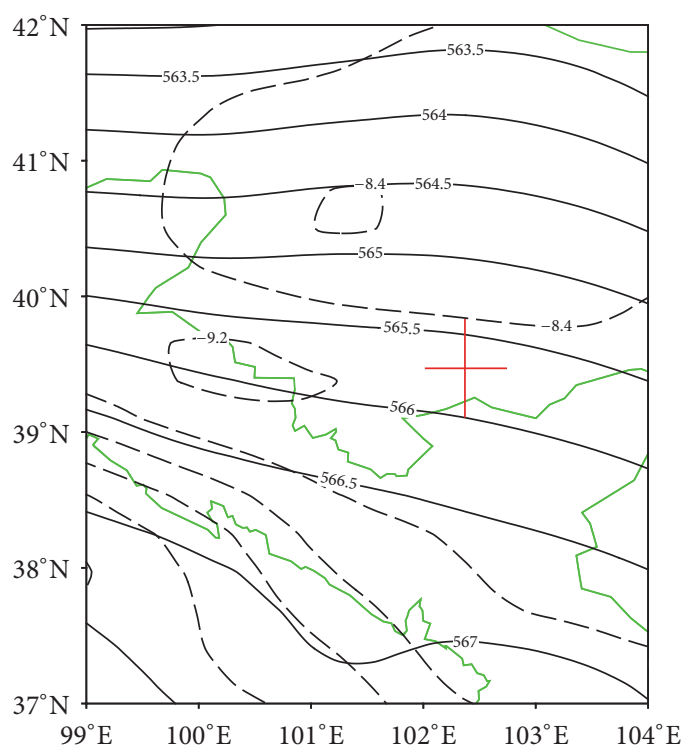

(a)

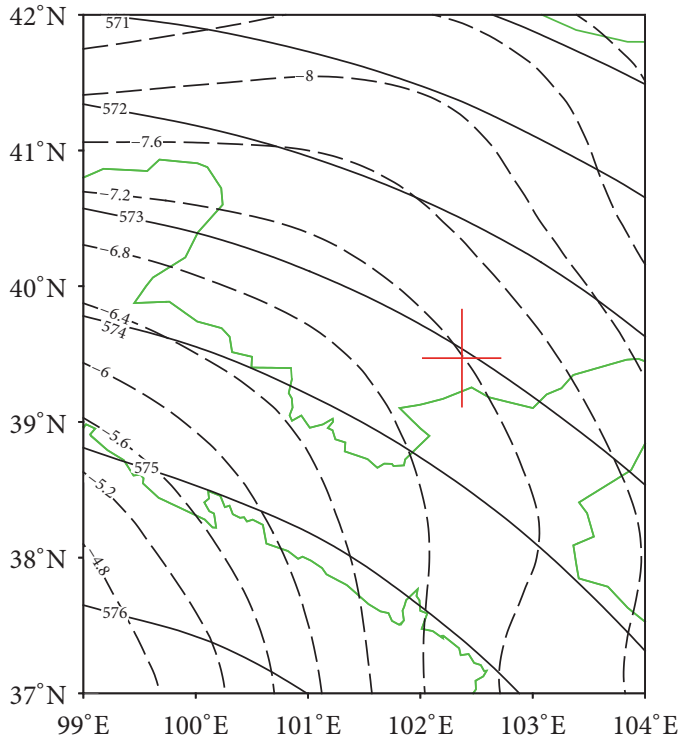

(c)

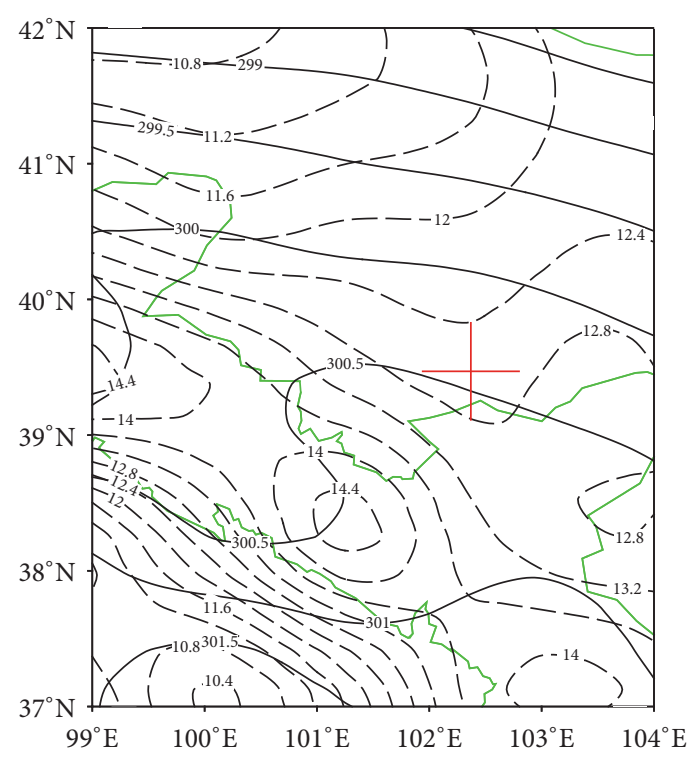

(b)

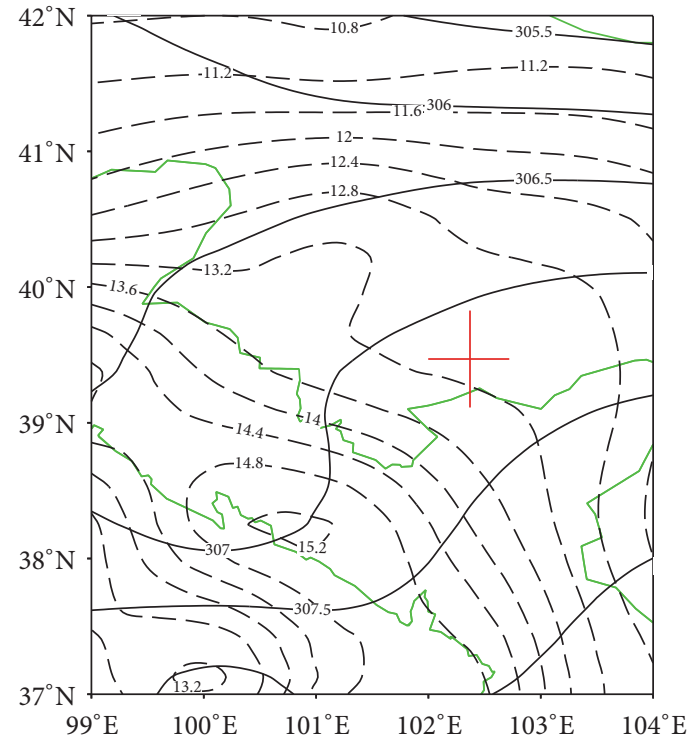

(d)

FIGURE 10: Atmospheric circulation in (a)-(b) $500 \mathrm{hPa}$ and $700 \mathrm{hPa}$ at $0600 \mathrm{UTC}$ on July 4 and (c)-(d) $500 \mathrm{hPa}$ and $700 \mathrm{hPa}$ at $0600 \mathrm{UTC}$ on August 30 (solid line: geopotential height, unit: gpm; dotted line: temperature, unit: Celsius degree; +: observation site).

advection from the ground to the upper air, which could easily result in the unstable atmospheric stratification and stronger turbulent motion.

The influence of temperature advection on ABL is mainly manifested that if warm advection controlled large areas of space, the surface temperature gradually rose. When the altitude of CBL was relatively low, the air rapidly mixed between the bottom and upper layer because of the entrainment effect at the bottom of warm advection, resulting in rapid development of CBL. The process of energy balance reached between the upper and low layer air was also a process for maintenance of CBL. So the distribution and strength of warm advection in the middle and high level have influence on development of ABL.

\section{Conclusion and Discussion}

In this study, the development of ABL in desert in midsummer and late summer was analyzed based on the data from two limited-period field observations performed in Badain Jaran Desert, and formation of thick CBL was explored by use of climate background, RML, surface thermal condition, and atmospheric circulation. Our major conclusions as a case were as follows: 
(1) Affected by topography of the Tibetan Plateau, the desert area was characterized by dryness and being rainless with severe dry convection, which provided favorable external conditions for the development of CBL.

(2) The thickness of CBL was more than $4,000 \mathrm{~m}$, and it showed a diurnal variation of three- to five-layer structure in clear days and the emergence time of fivelayer $\mathrm{ABL}$ structure was often seen in the sunset or sunrise.

(3) The diurnal variation of DSAT had a close relationship with the thickness of $\mathrm{ABL}$ regardless of midsummer or late summer. The development of CBL lagged behind DSAT. DSAT indirectly influenced the development of the boundary layer through turbulent heat flux and so forth.

(4) The integral value of sensible heat flux which rapidly converted by surface net in the budget of surface energy balance had a significant influence on the growth of CBL throughout daytime. And the cumulative effect of thick RML dominated the role after CBL got through the SBL, especially obvious in late summer.

(5) The development of CBL is promoted by the strong wind shear and large wind speed. The distribution of warm advection in high and low altitude could provide favorable environment for the development of CBL.

The preliminary study on the diurnal variation of $A B L$ and reasons for formation of thick CBL in Badain Jaran Desert was discussed by the observation data, but some problems still need to be further analyzed including the influence of atmospheric stability on thickness of CBL, the coupling process between RML and CBL.

Due to objective conditions, such as lack of infrastructure for continuous radiosonde observation in the internal part of desert, the analysis results had certain limitations, such as the two experiments that were carried out for only a few days. In addition, the accurate variation of $A B L$ at night has not yet been fully understood owing to fewer nocturnal radiosonde observation times. Many turbulence parameters can be estimated from the Eddy Covariance System observation data. It will provide the basis for the mechanism of deep ABL in convective weather conditions. In the next experiment, observation period and times will be prolonged and increased properly, especially the observation times of boundary layer at night so that the changes of $\mathrm{ABL}$ in the desert can be studied in a more careful manner.

\section{Competing Interests}

The authors declare that they have no competing interests.

\section{Acknowledgments}

The authors are thankful for the assistance of Dr. Han Bo, Dr. Zhang Shao Bo, Dr. Chen Hao, and other colleagues who took part in these works and devoted themselves to the smooth development of the experiments and integrity of valuable observational data in unfrequented desert region. This research was supported by National Natural Science Foundation of China (no. 41675020, 41575008), the China Special Fund for Meteorological Research in the Public Interest (GYHY201506001-04), and China Meteorological Administration Special Public Welfare Research Fund (GYHY201306066).

\section{References}

[1] A. K. Betts and J. H. Ball, "Budget analysis of FIFE 1987 sonde data," Journal of Geophysical Research, vol. 99, no. 2, pp. 36553666, 1994

[2] S. A. Margulis and D. Entekhabi, "Boundary-layer entrainment estimation through assimilation of radiosonde and micrometeorological data into a mixed-layer model," Boundary-Layer Meteorology, vol. 110, no. 3, pp. 405-433, 2004.

[3] J. B. Moncrieff, J. M. Massheder, H. De Bruin et al., "A system to measure surface fluxes of momentum, sensible heat, water vapour and carbon dioxide," Journal of Hydrology, vol. 188-189, no. 1-4, pp. 589-611, 1997.

[4] S. M. Joffre, M. Kangas, M. Heikinheimo, and S. A. Kitaigorodskii, "Variability of the stable and unstable atmospheric boundary-layer height and its scales over a boreal forest," Boundary-Layer Meteorology, vol. 99, no. 3, pp. 429-450, 2001.

[5] S.-J. Lee and H. Kawai, "Mixing depth estimation from operational JMA and KMA wind-profiler data and its preliminary applications: examples from four selected sites," Journal of the Meteorological Society of Japan, vol. 89, no. 1, pp. 15-28, 2011.

[6] W. M. Angevine, A. B. White, and S. K. Avery, "Boundary-layer depth and entrainment zone characterization with a boundarylayer profiler," Boundary-Layer Meteorology, vol. 68, no. 4, pp. 375-385, 1994.

[7] A. Beljaars, "The impact of some aspects of the boundary layer scheme in the ECMWF model," in Proceedings of the Seminar on Parametrization of Sub-Grid Scale Physical Processes, 1995.

[8] A. K. Betts, P. Viterbo, A. Beljaars et al., "Evaluation of landsurface interaction in ECMWF and NCEP/NCAR reanalysis models over grassland (FIFE) and boreal forest (BOREAS)," Journal of Geophysical Research Atmospheres, vol. 103, no. 18, pp. 23079-23085, 1998.

[9] R. B. Stull, An Introduction to Boundary Layer Meteorology, vol. 13, Springer, 1988.

[10] S.-J. Lee, J. Lee, S. J. Greybush, M. Kang, and J. Kim, "Spatial and temporal variation in PBL height over the Korean Peninsula in the KMA operational regional model," Advances in Meteorology, vol. 2013, Article ID 381630, 16 pages, 2013.

[11] S.-J. Lee, J. Kim, and C.-H. Cho, "An automated monitoring of atmospheric mixing height from routine radiosonde profiles over South Korea using a web-based data transfer method," Environmental Monitoring and Assessment, vol. 186, no. 5, pp. 3253-3263, 2014

[12] J. H. Marsham, D. J. Parker, C. M. Grams, B. T. Johnson, W. M. F. Grey, and A. N. Ross, "Observations of mesoscale and boundary-layer scale circulations affecting dust transport and uplift over the Sahara," Atmospheric Chemistry and Physics, vol. 8, no. 23, pp. 6979-6993, 2008. 
[13] M. Gamo, "Thickness of the dry convection and large-scale subsidence above deserts," Boundary-Layer Meteorology, vol. 79, no. 3, pp. 265-278, 1996.

[14] Q. He and A. Mamtimin, "Characteristics of wind velocity, humidity and temperature profiles near surface layer on a cloudy day in spring in the hinterland of taklimakan desert," Arid Meteorology, vol. 25, no. 2, pp. 22-28, 2007.

[15] M. Gamo, P. Goyal, M. Kumari, U. C. Mohanty, and M. P. Singh, "Mixed-layer characteristics as related to the monsoon climate of New Delhi, India," Boundary-Layer Meteorology, vol. 67, no. 3, pp. 213-227, 1994.

[16] C. Flamant, J.-P. Chaboureau, D. J. Parker et al., "Airborne observations of the impact of a convective system on the planetary boundary layer thermodynamics and aerosol distribution in the inter-tropical discontinuity region of the West African Monsoon," Quarterly Journal of the Royal Meteorological Society, vol. 133, no. 626 A, pp. 1175-1189, 2007.

[17] M. J. Suarez, A. Arakawa, and D. A. Randall, “The parameterization of the planetary boundary layer in the UCLA general circulation model: formulation and results," Monthly Weather Review, vol. 111, no. 11, pp. 2224-2243, 1983.

[18] J.-P. Goutorbe, T. Lebel, A. Tinga et al., "HAPEX-Sahel: a largescale study of land-atmosphere interactions in the semi-arid tropics," Annales Geophysicae, vol. 12, no. 1, pp. 53-64, 1994.

[19] Q. Zhang, Y. Zhao, S. Wang, and F. Ma, "A study on atmospheric thermal boundary layer structure in extremely arid desert and Gobi region on the clear day in summer," Advances in Earth Science, vol. 22, no. 11, pp. 8-15, 2007.

[20] T. Takemi, "Structure and evolution of a severe squall line over the arid region in Northwest China," Monthly Weather Review, vol. 127, no. 6, pp. 1301-1309, 1999.

[21] M. Z. Wang, H. Lu, H. Ming, and J. Zhang, "Vertical structure of summer clear-sky atmospheric boundary layer over the hinterland and southern margin of Taklamakan Desert," Meteorological Applications, vol. 23, no. 3, pp. 438-447, 2016.

[22] M. Wang, W. Wei, Q. He, Y. Yang, L. Fan, and J. Zhang, "Summer atmospheric boundary layer structure in the hinterland of Taklimakan Desert, China," Journal of Arid Land, vol. 8, no. 6, pp. 846-860, 2016.

[23] Q. Zhang, J. Zhang, J. Qiao, and S. Wang, "Relationship of atmospheric boundary layer depth with thermodynamic processes at the land surface in arid regions of China," Science China Earth Sciences, vol. 54, no. 10, pp. 1586-1594, 2011.

[24] Y. Ma, M. Menenti, and R. Feddes, "Parameterization of heat fluxes at heterogeneous surfaces by integrating satellite measurements with surface layer and atmospheric boundary layer observations," Advances in Atmospheric Sciences, vol. 27, no. 2, pp. 328-336, 2010.

[25] Q. Zhang, R. H. Huang, and S. Wang, "NWC-ALIEX and its research advances," Advanced Earth Science, vol. 20, no. 4, pp. 427-441, 2005.

[26] Q. Zhang, G. A. Wei, and P. Hou, "Observation studies of atmosphere boundary layer characteristic over Dunhuang gobi in early summer," Plateau Meteorology, vol. 23, no. 5, pp. 587$597,2004$.

[27] J. Zhao, "A simulative study of the thermal mechanism for development of the convective boundary layer in the arid zone of northwest China," Acta Meteorologica Sinica, vol. 69, no. 6, pp. 1029-1037, 2011.
[28] B. Han, S. Lü, and Y. Ao, "Development of the convective boundary layer capping with a thick neutral layer in Badanjilin: observations and simulations," Advances in Atmospheric Sciences, vol. 29, no. 1, pp. 177-192, 2012.

[29] X. Song, H. Zhang, J. Chen, and S.-U. Park, "Flux-gradient relationships in the atmospheric surface layer over the gobi desert in China," Boundary-Layer Meteorology, vol. 134, no. 3, pp. 487-498, 2010.

[30] N. Lancaster, R. Greeley, and K. R. Rasmussen, "Interaction between unvegetated desert surfaces and the atmospheric boundary layer: a preliminary assessment," in Aeolian Grain Transport, vol. 2 of Acta Mechanica Supplementum, pp. 89-102, Springer, Vienna, Austria, 1991.

[31] P. Seibert, F. Beyrich, S.-E. Gryning, S. Joffre, A. Rasmussen, and P. Tercier, "Review and intercomparison of operational methods for the determination of the mixing height," Atmospheric Environment, vol. 34, no. 7, pp. 1001-1027, 2000.

[32] Y.-K. Hyun, K.-E. Kim, and K.-J. Ha, "A comparison of methods to estimate the height of stable boundary layer over a temperate grassland," Agricultural and Forest Meteorology, vol. 132, no. 1-2, pp. 132-142, 2005.

[33] T. D. Crum, R. B. Stull, and E. W. Eloranta, "Coincident lidar and aircraft observations of entrainment into thermals and mixed layers," Journal of Applied Meteorology, vol. 26, no. 7, pp. 774$788,1987$.

[34] Q. Zhang and S. Wang, "A study of the atmospheric boundary layer structure during a clear day in the arid region of Northwest China," Acta Meteorologica Sinica, vol. 23, no. 3, pp. 327-337, 2009 (Chinese).

[35] D. A. Haugen, J. C. Kaimal, and E. F. Bradley, "An experimental study of Reynolds stress and heat flux in the atmospheric surface layer," Quarterly Journal of the Royal Meteorological Society, vol. 97, no. 412, pp. 168-180, 1971.

[36] Q. Zhang and S. Wang, "A study of the atmospheric boundary layer structure during a clear day in the arid region of Northwest China," Journal of Meteorological Research, vol. 23, no. 3, pp. 327-337, 2009.

[37] H. Shan, Simulation and Research of Boundary Layer Processes in Arid and Semiarid Areas of Northwest by Mesoscale Meteorological Model, Lanzhou University, 2011 (Chinese).

[38] M. A. F. Medeiros and M. Gaster, "The production of subharmonic waves in the nonlinear evolution of wavepackets in boundary layers," Journal of Fluid Mechanics, vol. 399, pp. 301318, 1999.

[39] Z. X. Sun and Q. Zhang, "Analysis of climate characteristics of land surface temperature and energy in the semiarid region in the Loess Plateau," Journal of Desert Research, vol. 31, pp. 13021308, 2011.

[40] H. Zuo, X. Xiao, Q. Yang, L. Dong, J. Chen, and S. Wang, "On the atmospheric movement and the imbalance of observed and calculated energy in the surface layer," Science China Earth Sciences, vol. 55, no. 9, pp. 1518-1532, 2012.

[41] J. Cuesta, J. H. Marsham, D. J. Parker, and C. Flamant, "Dynamical mechanisms controlling the vertical redistribution of dust and the thermodynamic structure of the West Saharan atmospheric boundary layer during summer," Atmospheric Science Letters, vol. 10, no. 1, pp. 34-42, 2009. 

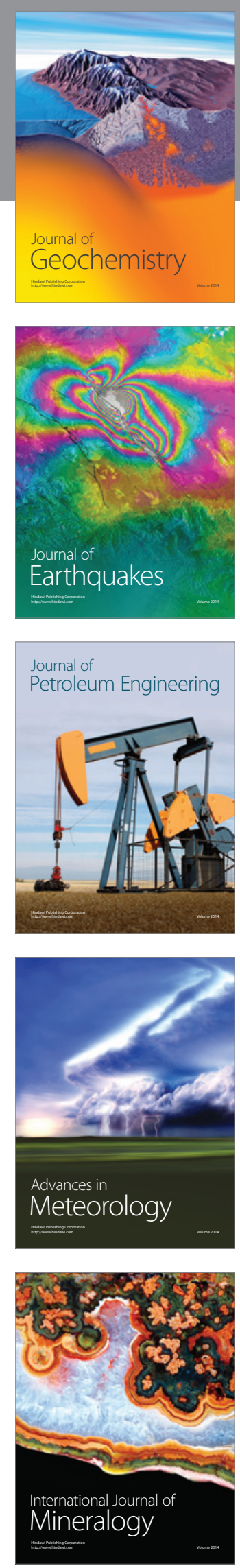
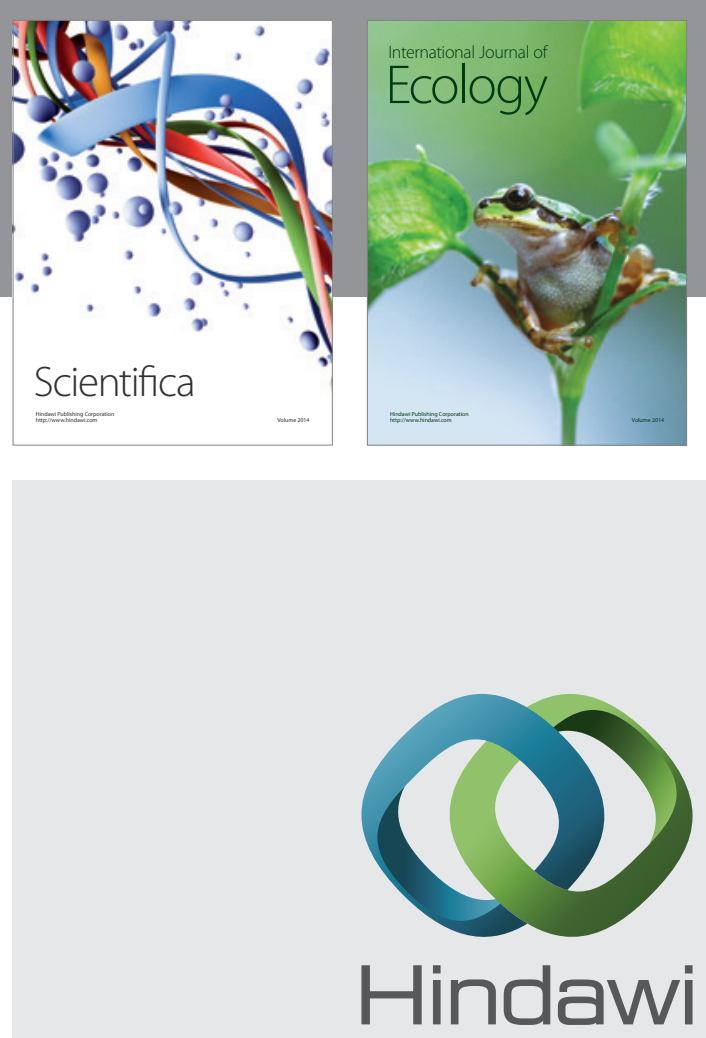

Submit your manuscripts at

https://www.hindawi.com
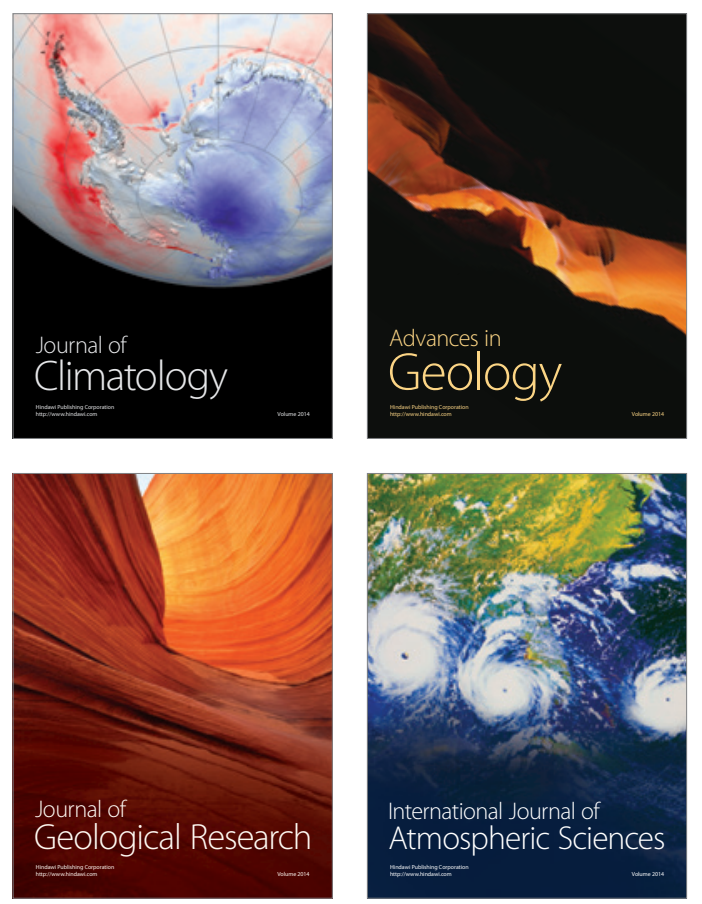

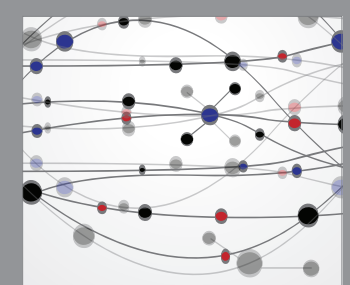

The Scientific

\section{World Journal}
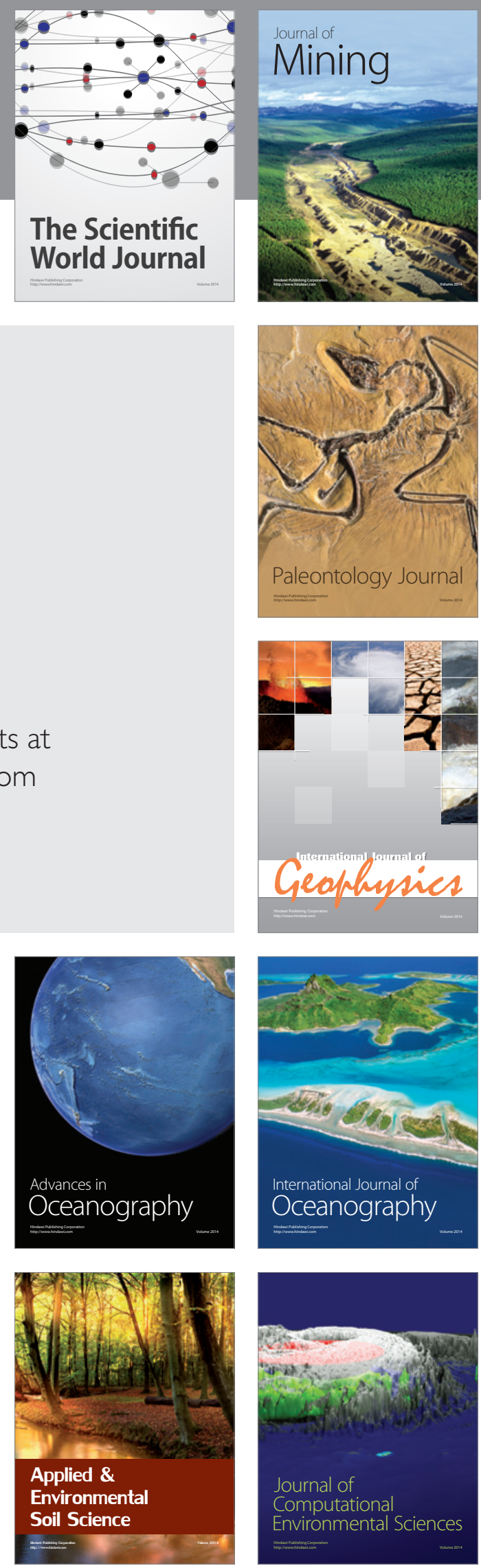